\title{
Implementação de um Novo Layout Visando à Competitividade Global no Setor de Customização da Maior Indústria de Confecção de Vestuário da América Latina
}

\author{
Rafaella de Freitas Gurgel \\ Universidade Federal do Rio Grande do Norte, UFRN, Brasil \\ rafaellagurgel_@hotmail.com \\ Hélio Roberto Hékis \\ Universidade Federal do Rio Grande do Norte, UFRN, Brasil \\ hekis1963@gmail.com \\ Ricardo Pires de Souza \\ Universidade Federal do Rio Grande do Norte, UFRN, Brasil \\ ripiso@gmail.com \\ Lawrence Cézar Medeiros Araújo de Moura \\ Universidade Federal do Rio Grande do Norte, UFRN, Brasil \\ lawrencemedeiros89@gmail.com \\ Maíra Luciano Sidrim \\ Universidade Federal do Rio Grande do Norte, UFRN, Brasil \\ mairasidrim@gmail.com \\ Lara Cavalcante Freitas da Silva \\ Universidade Federal do Rio Grande do Norte, UFRN, Brasil \\ larafreitas2@hotmail.com
}

\section{RESUMO}

Um incremento na competitividade de uma empresa pode ser alcançado com a apresentação de um layout eficiente, que tende a proporcionar não só economia, como também melhoria na interatividade entre a produção e a demanda dos produtos. Dessa forma, neste estudo, objetiva-se avaliar e otimizar o arranjo físico do setor de customização de peças de vestuário da maior indústria de confecção de vestuário da América Latina, por meio do Planejamento Sistemático de Layout (SLP). Três novos layouts foram elaborados e, o que melhor atendeu às necessidades do projeto foi implementado, gerando melhorias como: eliminação do maior fluxo de deslocamento entre os carrosséis e as esteiras, maior integração entre os demais setores, redução da quantidade de operadores no setor, aumento da qualidade final do produto, redução de perdas e retrabalho, melhoria 
das condições ergonômicas dos operadores e redução do lead time da peça.

PALAVRAS-CHAVE: Projeto de layout. Gestão de produção e operações. Fluxos de processos. Planejamento Sistemático de Layout (SLP).

\section{Implementation of a New Layout Aimed at Global Competitiveness in the Sector of Customization of the Greater Garment Making Industry in Latin America}

\section{ABSTRACT}

An increase in the competitiveness of a company can be achieved by presenting an efficient layout, which tends to provide not only savings but also improvements in the interactivity between the production and demand of the products. Thus, this article goals to evaluate and optimize the physical arrangement in the customization sector of the largest garment making industry in Latin America, through the Systematic Layout Planning (SLP). Three new layouts have been presented to the company's board, which chose the layout $\mathrm{C}$. The new layout was implemented, which resulted in the following improvements: elimination of the largest displacement flow between the carousels and conveyors, integration among remaining sectors, reduction of the number of operators in the sector of customization, increase in the quality of the final product, a reducing on the losses and rework, improvement in the operator's ergonomic conditions and a reducing on the part's lead time.

KEY-WORDS: Layout project. Production and operations management. Process flow. Systematic Layout Planning (SLP). 


\section{INTRODUÇÃo}

Historicamente, pode-se observar a gradativa aceleração das mudanças no cenário industrial ao longo dos anos. As organizações interagem com o seu ambiente, sofrem as influências da dinâmica deste e desenvolvem ajustes para adaptar-se às novas condições. Esse cenário industrial apresenta-se cada vez mais mutável, imprevisível e competitivo. A concorrência assume escalas globais e as empresas são forçadas a aperfeiçoar seus processos de gestão e de produção, buscando a melhoria constante de seu desempenho para se manterem competitivas.

Devido à necessidade de adaptação ao mercado consumidor exigente e competitivo, as empresas precisam mostrar que estão prontas para atender uma demanda que não aceita falta de qualidade e muito menos espera. O layout é uma ferramenta importante no processo produtivo, pois está diretamente ligado à programação, ao controle e à organização da produção, levando a melhorias no fluxo produtivo (Britto, Melo, Arcieri \& Barreto, 2015).

Assim, o planejamento e a mudança de layout desempenham um papel importante nos sistemas de produção atuais, contribuindo fortemente para a competitividade das organizações (Emami \& Nookabadi, 2013). O indicador mais importante para a avaliação da eficiência de um layout é o custo de manuseio de materiais, ao qual pode ser atribuído de $20 \%$ a $50 \%$ dos custos totais de fabricação de uma organização (Tompkins \& White, 1984).

Na indústria de confecção, especialmente no setor de customização, a atualização da disposição das instalações com maior frequência faz-se necessária, pois é grande a quantidade de produtos e flutuações de volumes. Essas atualizações trazem como benefício a redução de custos e a melhoria da produtividade. Desse modo, surge o problema desta pesquisa: como a modificação de um layout pode contribuir para aumentar a competitividade de uma indústria de confecção de vestuário?

À luz dessa reflexão, o objetivo principal do presente estudo é identificar os impactos causados pela modificação de layout do setor de customização da maior indústria de confecção de vestuário da América 
Latina. Já os objetivos específicos são: mapear os processos do setor de customização da empresa em estudo, aplicar o Planejamento Sistemático de Layout (SLP), elaborar três propostas de layouts para o setor estudado, implementar uma dessas propostas e avaliar os impactos causados por essa modificação.

\section{REVISÃO BIBLIOGRÁFICA}

\subsection{A INDÚSTRIA TÊXTIL NO BRASIL}

Historicamente, o setor têxtil brasileiro desenvolveu-se sob a proteção do governo até o fim da década de 1980. Suas atividades produtivas eram destinadas e focadas em um mercado praticamente imune a produtos estrangeiros e estavam inseridas em um cenário de pouca concorrência nacional. No início da década de 1990, ocorreu a abertura do mercado brasileiro às importações, que trouxe ao Brasil produtos importados com preços baixos, com os quais as mercadorias nacionais não conseguiam concorrer, e forçou as empresas nacionais a se reestruturarem.

O processo de reestruturação da indústria têxtil-confecções iniciouse lentamente. As empresas inicialmente posicionaram-se contra a entrada dos produtos importados, mas, em seguida, com a estabilização econômica, os empresários enxergaram as facilidades dessa abertura e, junto a isso, as possibilidades de modernização do parque industrial e seu alinhamento ao padrão produtivo internacional.

Segundo a Associação Brasileira da Indústria Têxtil (ABIT, 2008), apesar de todas as dificuldades, os investimentos em modernização foram elevados na década de 1990, e estima-se que os investimentos totais na cadeia têxtil nacional tenham alcançado cerca de US\$ 6 bilhões. Os investimentos realizados colocaram o Brasil em patamar tecnológico similar ao dos países líderes do setor. Os investimentos em tecnologia de ponta foram destinados principalmente às áreas de fiação, tecelagem e tinturaria/estamparia das empresas. O complexo têxtil brasileiro aumentou sua produtividade em função do grande esforço de investimento (Banco Nacional de Desenvolvimento Econômico e Social - BNDES, 2015). 
A característica estrutural básica da indústria de confecção, em nível mundial, é a grande heterogeneidade das unidades produtivas em termos de tamanho, escala de produção e padrão tecnológico (Pelissari, Gonzalez \& Vanalle, 2011). Já a indústria têxtil brasileira caracteriza-se pela sua grande diversificação no que se refere ao porte, à linha de produtos e ao estágio tecnológico e gerencial. O Brasil tem custos competitivos em relação aos concorrentes internacionais, principalmente nos itens energia e mão de obra.

\subsection{ARRANJO FÍSICO}

O arranjo físico de uma operação produtiva diz respeito ao posicionamento físico dos seus recursos transformadores. Isso significa decidir onde colocar todas as instalações, máquinas, equipamentos e pessoal da operação (Slack, Chambers \& Johnston, 2009). O estudo do arranjo físico pode possibilitar inúmeros benefícios à empresa e é realizado para que o processo ocorra dentro de um padrão máximo de economia. Um layout eficiente pode conferir à unidade fabril a obtenção de uma relação de maior interatividade entre a produção e a demanda dos produtos, o que incrementa uma maior competitividade na empresa (Emami \& Nookabadi, 2013; Britto et al., 2015).

Em contrapartida, segundo Schmenner (1995), layouts ruins podem causar uma série de consequências negativas para as operações de serviços, desde a criação de excessivas filas de produtos ou clientes até o aumento dos custos totais da operação.

O objetivo primordial das decisões sobre arranjo físico é apoiar a estratégia competitiva da operação, buscando um alinhamento entre as características do arranjo físico escolhido e as prioridades competitivas da organização (Corrêa \& Corrêa, 2006). A disposição física determina o fluxo do processo e, de acordo com a natureza do processo, o arranjo físico da produção pode enquadrar-se dentro de uma das quatro categorias básicas já consolidadas na literatura da área: layout posicional, funcional, linear e celular (Gaither \& Frazier, 2001; Villar \& Nóbrega Júnior, 2004; Garcia-Diaz \& Smith, 2008). 


\subsection{PLANEJAMENTO SISTEMÁTICO DE LAYOUT - SLP}

O Planejamento Sistemático de Layout, ou Systematic Layout Planning - SLP, é um método de planejamento de arranjo físico e propõe procedimentos para identificação, avaliação e visualização dos elementos e das áreas de uma instalação (Murther, 1973). A base desse método está na priorização dos fluxos de materiais entre os diversos setores da empresa, de modo a minimizar a distância percorrida pelos materiais movimentados em grandes quantidades. No entanto, são também necessárias algumas avaliações de conveniência, de proximidade ou distanciamento entre os setores, levando em consideração todos os detalhes relacionados aos processos produtivos (Tortorella \& Fogliatto, 2008).

O procedimento do SLP pode ser usado para desenvolver inicialmente um layout de blocos e, a partir deste, obter o detalhamento de cada setor planejado (Tortorella \& Fogliatto, 2008). O modelo de procedimentos do SLP pressupõe que o projeto de um arranjo físico deve estar apoiado em três conceitos fundamentais (Muther, 1973; Muther \& Wheeler, 2000):

- $\quad$ inter-relações - grau relativo de dependência ou proximidade entre as atividades;

- $\quad$ espaço - quantidade, tipo e forma ou configuração dos itens a serem posicionados;

- $\quad$ ajuste - arranjo das áreas e equipamentos da melhor maneira possível.

O primeiro passo para a aplicação do SLP é o levantamento do fluxo de processo e das quantidades transportadas entre setores produtivos, serviços de suporte, etc. Baseando-se nesses dados, monta-se um diagrama De-Para (ou diagrama de fluxo), onde se compilam as distâncias e jornadas diárias de um setor para outro. Dependendo do caso, pode haver diferenças consideráveis com relação ao custo de mover materiais ou clientes entre os centros de trabalho, sendo necessário calcular o custo unitário de transporte e multiplicá-lo pelos dados do fluxo, para chegar-se ao resultado do custo por distância percorrida. 
Com o levantamento de informações relativas à movimentação entre os setores, tabuladas no diagrama, pode-se classificar a proximidade entre os setores em: A - Absolutamente importante; E - Especialmente importante; I - Importante; O - Pouco Importante; U - Desprezível (Lin, Liu, Wang \& Liu, 2013). Com essa classificação entre os diversos setores, faz-se a carta de interligações preferenciais (Figura 1), que determina os níveis de relacionamento entre os centros de atividades, evidenciando se um departamento deve ou não ficar próximo de cada um dos demais.

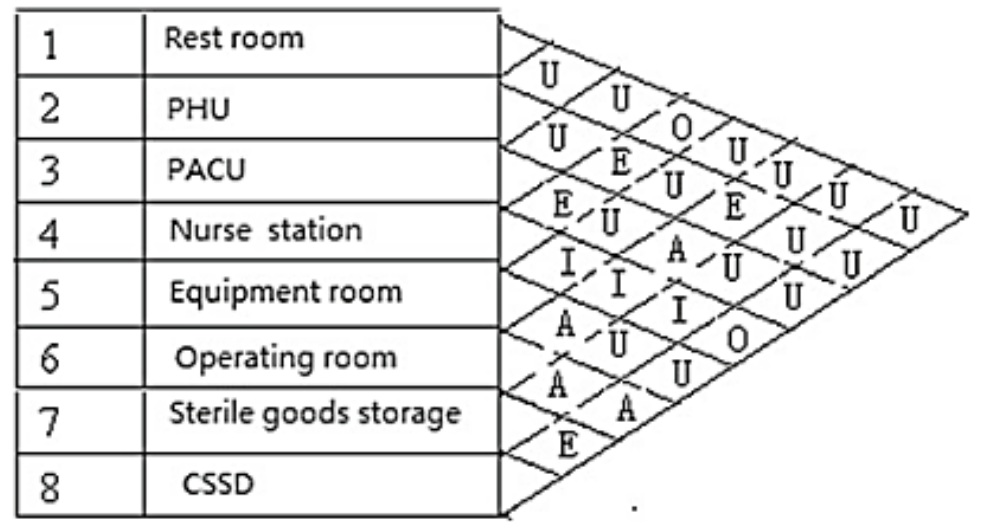

\section{Figura 1: Modelo de carta de interligações preferenciais}

Fonte: Lin et al. (2013)

Haverá diversas maneiras de se arranjarem as áreas calculadas em função de sua conveniência de proximidade entre os setores envolvidos. Assim, é conveniente a elaboração de diversas alternativas para que se possa escolher qual a melhor entre elas. Ao se agruparem as áreas, deve-se levar em consideração o espaço disponível para a disposição das máquinas ou, no caso de plantas a serem construídas, a forma adequada do galpão (Francischini \& Fegyveres, 1997).

Em resumo, Muther (1973) descreve a metodologia SLP com os seguintes procedimentos para elaboração de arranjos físicos: (i) coleta de informações; (ii) análise dos fluxos de materiais e as inter-relações entre as atividades; (iii) verificação do espaço disponível e o necessário; (iv) elaboração de um diagrama de relacionamento; ( $v$ ) apreciação do que pode ou não ser alterado e, por fim, são elaboradas propostas de layouts otimizados. 
Assim, o estudo de arranjo físico de uma organização tem muitas implicações práticas e estratégicas fundamentais para otimização de processos, organização do espaço físico e melhor disposição dos recursos disponíveis (Petry, 2015).

\section{MÉTODOS}

O presente estudo está delineado no tipo exploratório descritivo em seu objetivo, pois, segundo Gil (2009, p. 42), tem "como objetivo primordial a descrição de características de determinada população ou fenômeno", e sua principal característica é utilizar técnicas padronizadas de coleta de dados. A pesquisa é caracterizada como aplicada em sua natureza, pois objetiva gerar conhecimentos para aplicação prática dirigidos à solução de problemas específicos (Silva \& Menezes, 2005).

Considerando-se os procedimentos técnicos, utilizou-se o estudo de caso realizado em um setor de customização da maior indústria de confecção de vestuário da América Latina, pois consiste no estudo profundo e exaustivo de um ou poucos objetos, de maneira que permita seu amplo e detalhado conhecimento (Gil, 2009).

Inicialmente, um estudo exploratório foi necessário para proporcionar maior familiaridade com o problema enfrentado pela empresa. Após a compreensão do problema, iniciou-se a coleta de dados com a anotação de todas as operações e movimentações dos colaboradores do chão de fábrica, possibilitando a elaboração do fluxo de distância em metros e a verificação da quantidade de jornadas diárias entre os carrosséis e os setores diretamente ligados à produção, com o intuito de decidir sobre o grau de importância de proximidade entre os setores diretamente ligados à produção.

$\mathrm{Na}$ sequência, analisou-se a capacidade diária das esteiras polimerizadeiras, identificadas como gargalo na parte final do processo. Confrontando-se os resultados obtidos a partir da coleta de dados, com os dados numéricos de produção média diária de aproximadamente um ano das máquinas de estamparia (carrosséis), foi possível verificar a 
necessidade de aquisição de mais esteiras polimerizadeiras e decidir, por meio do método payback, sobre o investimento.

A partir de então, utilizou-se o método do Planejamento Sistemático de Layout (SLP) e, seguindo suas etapas, pôde-se calcular a eficácia do arranjo físico atual e propor o esqueleto de um novo arranjo físico ideal. Foram desenhadas, apresentadas e analisadas três propostas, com especificações técnicas diferentes, das quais, uma foi escolhida pela diretoria industrial da empresa e, posteriormente, implementada na prática. Para a formalização das propostas de layout, foi utilizado um programa denominado sketch up.

\section{ESTUDOS DE CASO: SETOR DE CUSTOMIZAÇÃO DA MAIOR INDÚSTRIA DE CONFECÇÃO DE VESTUÁRIO DA AMÉRICA LATINA}

As atividades da organização estudada foram iniciadas no fim da década de 1940, com a venda de roupas em pequenas lojas no Nordeste do Brasil. Atualmente a empresa conta com três unidades fabris, com áreas construídas de $9.800 \mathrm{~m}^{2}, 60.000 \mathrm{~m}^{2}$ e $150.000 \mathrm{~m}^{2}$, todas situadas no Nordeste do Brasil. A organização conta, ainda, com dois grandes centros de distribuição, um no Nordeste do Brasil com área de $55.000 \mathrm{~m}^{2}$ e outro no Sudeste do país com $86.000 \mathrm{~m}^{2}$ que, junto com a transportadora própria, são responsáveis pela logística de distribuição das quase 200 mil peças produzidas por dia.

Inicialmente, a indústria decidia o que iria produzir e fornecia seus produtos a milhares de clientes espalhados pelo Brasil, inclusive para a sua rede própria de varejo. Ou seja, os produtos da fábrica poderiam ser encontrados em milhares de pontos de vendas. Recentemente, o grupo em estudo passou por uma transformação estratégica que tem resultado em bons frutos. A organização em estudo deixou de ser apenas uma empresa verticalizada para ser uma empresa completamente integrada, com um único e potencial cliente, que é a rede própria de varejo. Essa mudança estratégica tem proporcionado ótimos resultados, gerando uma grande agilidade na chegada de produtos à loja, aproveitando assim todas as oportunidades de venda, já que a moda é um produto obsoleto. 
Atualmente, o grupo está presente na maioria dos estados brasileiros por meio das suas lojas que crescem cada dia mais. Desde a sua fundação até os dias de hoje, o objetivo do grupo é comercializar produtos de alta qualidade a preços baixos, sempre buscando satisfazer e agregar valor a seus clientes.

O setor de customização da empresa está implementado dentro de sua maior planta fabril e é o responsável pela fase de beneficiamento, na qual é agregado maior valor ao produto. Na fase de beneficiamento ou customização do produto, a qualidade, a produtividade e a flexibilidade são essencialmente importantes, pois uma das características da moda é a sua efemeridade. Isso significa que o prazo de validade da moda é muito curto.

O setor da customização é o responsável pela adaptação da peça às preferências do consumidor, ou seja, pela personalização da peça. Com a recente mudança estratégica do grupo, a qualidade, a produtividade e a flexibilidade, somadas ao fator agilidade, devem estar ligadas diretamente à estrutura tecnológica da organização e às habilidades de seus recursos humanos, outro setor também muito visado atualmente pela indústria.

\section{RESULTADOS E DISCUSSÕES}

\subsection{MAPEAMENTO DE PROCESSOS}

O fluxograma do mapeamento da primeira parte do processo é exposto na Figura 2.

\begin{tabular}{|l|l|l|}
\hline 1- Posicionar peça na máquina \\
cuidadosamente
\end{tabular}




\section{Figura 2: Mapeamento do fluxo da primeira parte do processo de customização}

A produção é iniciada e, dependendo do número de telas e do grau de dificuldade da peça, ela é produzida mais rapidamente ou mais lentamente. O operário responsável retira a peça da máquina e a deposita em uma mesa, que fica localizada próxima ao carrossel.

Aglomera-se sobre essa mesa uma peça sobre a outra, até formar um atado, que é enrolado e preso junto com sua etiqueta. Muitas vezes a tinta passa de uma peça para outra, gerando uma situação de retrabalho e às vezes perda de peças. Os atados enrolados são guardados em um balcão próximo ao carrossel e esperam a retirada por um operário que trabalha na esteira.

O mapeamento do fluxo da segunda parte do processo é mostrado na Figura 3.

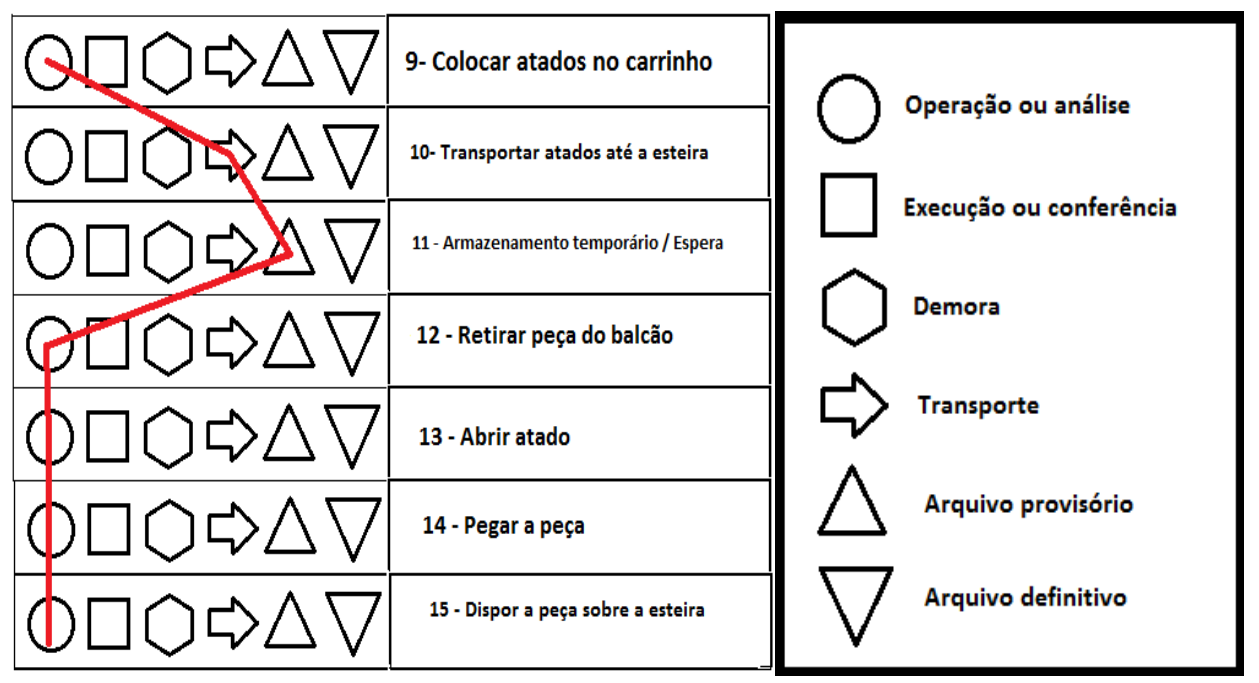

\section{Figura 3: Mapeamento do fluxo da segunda parte do processo de customização}

A segunda parte do processo inicia-se quando o operário da esteira recolhe os atados produzidos por cada máquina, hora a hora, até encher o carrinho. Então, o operário retorna à esteira e organiza os atados em outro balcão, onde as peças novamente aguardam períodos que chegam a no máximo 48 horas em dias de alta produção.

Nesses dias, formam-se filas de produtos na esteira, ou gargalos, até que as peças finalmente sejam polimerizadas. Todas as peças devem 
passar pela esteira, a uma temperatura de aproximadamente $160^{\circ} \mathrm{C}$ por um tempo de três minutos na câmara quente da esteira, para uma cura eficiente, que resulta em maior fixação da tinta na peça e maior qualidade. Ao finalizar-se a segunda parte do processo, as peças prontas são encaminhadas para a alfândega, onde será registrada sua saída do setor.

Antes de propor uma mudança de layout, é necessário o conhecimento do layout original, que é demonstrado na Figura 4.

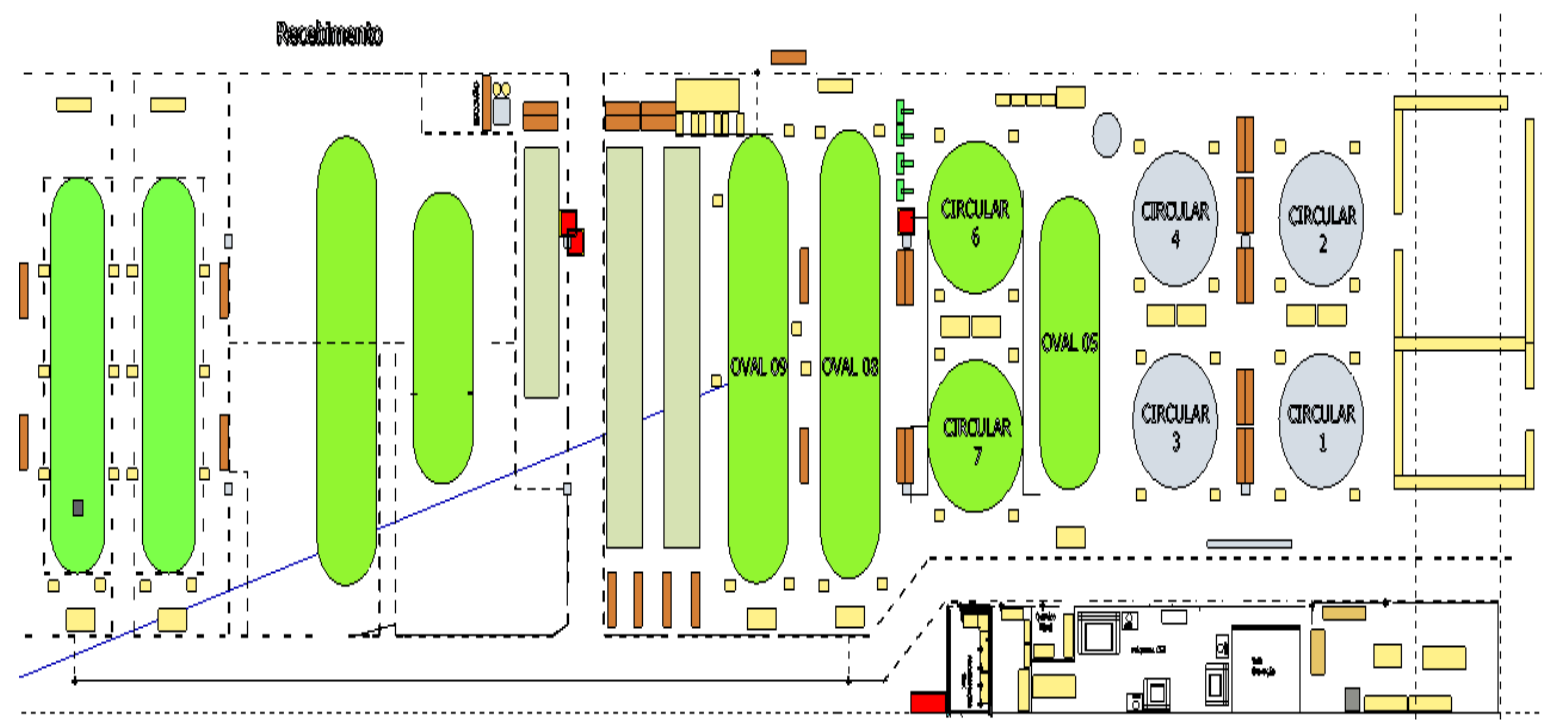

Figura 4: Layout original

Após a observação sistemática de todo o processo, optou-se por priorizar os processos do chão de fábrica, coletando e analisando os fluxos de pessoas e materiais da produção propriamente dita, por serem fluxos mais intensos, confusos e cruzados. Em seguida, observaram-se os fluxos do setor como um todo, juntando-se o desenvolvimento e a produção.

\subsection{APLICAÇÃO DO SLP (SYSTEMATIC LAYOUT PLANNING)}

$\mathrm{Na}$ aplicação do SLP, a primeira etapa foi a elaboração dos diagramas de fluxos de pessoas e materiais no chão de fábrica. Para isso, inicialmente elaborou-se um diagrama de fluxo da distância em metros e da quantidade de jornadas diárias entre os carrosséis e os setores diretamente ligados à produção: colorimetria, fotogravação e esteira polimerizadeira.

A quantidade de jornadas diárias de cada trabalhador foi acompanhada diariamente e contabilizada por meio de uma tabela 
previamente concebida, por um período de tempo necessário. Suas rotas foram observadas e as distâncias que elas representam foram medidas. Os dados estão compilados nas Tabelas 1 e 2.

Tabela 1: Diagrama De-Para Produção: Distância em Metros

\begin{tabular}{c|c|c|c}
\hline & DISTÂNCIA EM METROS (m) & \\
\hline De_Para & Fotoqravacão & Colorimetria & Esteira \\
\hline Circular 1 & 15 & 20 & 55 \\
\hline Circular 2 & 25 & 15 & 55 \\
\hline Circular 3 & 23 & 30 & 45 \\
\hline Circular 4 & 27 & 25 & 45 \\
\hline Oval 5 & 30 & 40 & 57 \\
\hline Circular 6 & 51 & 45 & 35 \\
\hline Circular 7 & 42 & 50 & 35 \\
\hline Oval 8 & 41 & 50 & 40 \\
\hline Oval 9 & 48 & 55 & 35 \\
\hline Oval 10 & 75 & 75 & 30 \\
\hline Oval 11 & 77 & 85 & 40 \\
\hline Oval 12 & 91 & 95 & 60 \\
\hline Oval 13 & 97 & 100 & 65 \\
\hline TOTAL & 642 & 685 & 597 \\
\hline IDAEvOLTA & $\mathbf{1 . 8 4} \mathbf{m}$ & $\mathbf{3 7 0} \mathbf{m}$ & $\mathbf{1 0 4}$ \\
\hline
\end{tabular}


Tabela 2: Diagrama De-Para Produção: Jornadas diárias

\begin{tabular}{c|c|c|c}
\hline \multicolumn{4}{|c}{ NÚMERO DE JORNADAS DIÁRIAS } \\
\hline DE/PARA & FOTOGRAVAÇÃO & COLORIMETRIA & ESTEIRA \\
\hline Circular 1 & 2,5 & 7 & 14 \\
\hline Circular 2 & 2,5 & 7 & 14 \\
\hline Circular 3 & 2,5 & 7 & 14 \\
\hline Circular 4 & 2,5 & 7 & 14 \\
\hline Oval 5 & 2,5 & 7 & 14 \\
\hline Circular 6 & 2,5 & 7 & 14 \\
\hline Circular 7 & 2,5 & 7 & 14 \\
\hline Oval 8 & 2,5 & 7 & 14 \\
\hline Oval 9 & 2,5 & 7 & 14 \\
\hline Oval 10 & 2,5 & 7 & 14 \\
\hline Oval 11 & 2,5 & 7 & 14 \\
\hline Oval 12 & 2,5 & 7 & 14 \\
\hline Oval 13 & 2,5 & 7 & 14 \\
\hline TOTAL & $\mathbf{3 2 , 5}$ & $\mathbf{9 1}$ & $\mathbf{1 8 2}$ \\
\hline
\end{tabular}

Multiplicando-se os dados das jornadas diárias pela distância percorrida nas rotas, obtém-se o fluxo diário, representado na Tabela 3. 


\section{Tabela 3: Diagrama De-Para Produção: Distância (m) X Jornadas diárias}

\begin{tabular}{c|c|c|c}
\hline \multicolumn{5}{c}{ DISTÂNCIA $\mathbf{( m )}$ x JORNADAS } \\
\hline DE/ PARA & FOTOGRAVAÇÃO & COLORIMETRIA & ESTEIRA \\
\hline Circular 1 & 37,5 & 140 & 770 \\
\hline Circular 2 & 62,5 & 105 & 770 \\
\hline Circular 3 & 57,5 & 210 & 630 \\
\hline Circular 4 & 67,5 & 175 & 630 \\
\hline Oval 5 & 75 & 280 & 798 \\
\hline Circular 6 & 127,5 & 315 & 490 \\
\hline Circular 7 & 105 & 350 & 490 \\
\hline Oval 8 & 102,5 & 350 & 560 \\
\hline Oval 9 & 120 & 385 & 490 \\
\hline Oval 10 & 187,5 & 525 & 420 \\
\hline Oval 11 & 192,5 & 595 & 560 \\
\hline Oval 12 & 227,5 & 665 & 840 \\
\hline Oval 13 & 242,5 & 700 & 910 \\
\hline TOTAL & $\mathbf{1 . 6 0 5}$ & $\mathbf{4 . 7 9 5}$ & $\mathbf{8 . 3 5 8}$ \\
\hline IDA E VOLTA & $\mathbf{3 . 2 1 0 ~} \mathbf{m}$ & $\mathbf{9 . 5 9 0 ~ \mathbf { ~ }}$ & $\mathbf{1 6 . 7 1 6} \mathbf{~ m}$ \\
\hline
\end{tabular}

O fluxo diário percorrido pelos operários em metros é mostrado na Tabela 3. Dos três setores responsáveis pela produção, a rota entre os carrosséis e a esteira polimerizadeira teve o maior fluxo, com aproximadamente $16.716 \mathrm{~m} / \mathrm{dia}$, seguida pelo fluxo entre as rotas dos carrosséis e a colorimetria, com $9.590 \mathrm{~m} / \mathrm{dia}$, e, finalmente, o fluxo entre os carrosséis e a fotogravação obteve $3.210 \mathrm{~m} /$ dia. A partir desses dados, houve a construção da carta de interligações preferenciais (Figura 5), representando-se nela a importância de proximidade entre os setores estudados. 


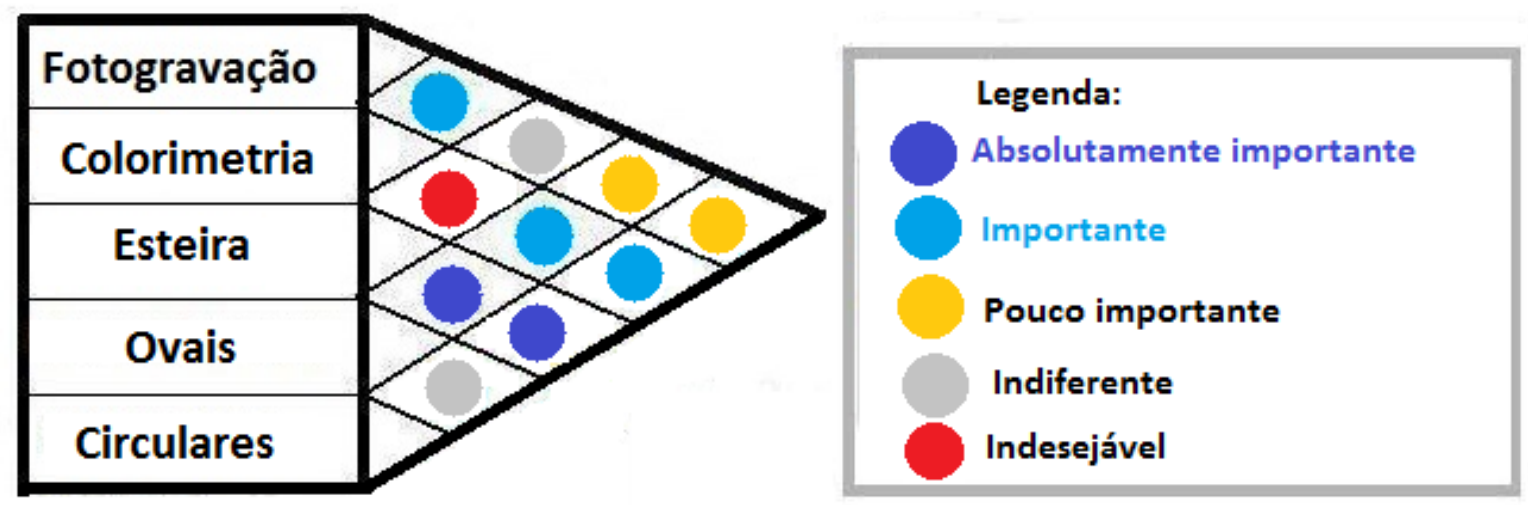

Figura 5: Carta de Interligações Preferenciais: chão de fábrica

Analisando-se as distâncias diárias percorridas, conclui-se que as esteiras devem estar tão próximas quanto possível dos carrosséis, com o intuito de reduzir ao máximo essa movimentação desnecessária, que não agrega valor ao produto.

Em segundo lugar, a colorimetria, ou setor de preparo das pastas, que totaliza um fluxo diário de aproximadamente 9.560 metros, encontra-se no final do setor, longe da maioria das máquinas. Pelo fluxo total diário observado, deve-se centralizar esse setor entre os carrosséis, reduzindo também fluxos que não agregam valor ao produto, de modo que este fique mais integrado com a produção, aumentando o poder de comunicação e a eficiência de suas operações.

Em terceiro lugar, tem-se a fotogravação, que também deve estar próxima, porém com menor grau de importância, já que a distância das rotas é menor.

Com auxílio do mapeamento de interligações preferenciais, percebese que os carrosséis de estampa devem estar o mais próximo possível de uma esteira, de modo que o mesmo colaborador que retira a peça da máquina, coloque-a sobre a esteira. Sabe-se também que devem ser adquiridas mais duas esteiras polimerizadeiras pequenas, totalizando cinco.

Uma nova etapa do processo foi a verificação dos fluxos de material em todo o setor de customização, assim nas Tabelas 4 e 5 organizam-se os dados coletados da movimentação dos fluxos de material do setor de customização. 


\section{Tabela4: Diagrama De-Para: Distância em Metros}

\begin{tabular}{l|c|c|c|c|c|c|c}
\hline \multicolumn{1}{c|}{ De / Para } & Alfândega & Desenvolvimento & Protótipo & Fotogravação & Programação & Colorimetria & Produção \\
\hline Alfândega & 0 & 30 & 15 & 180 & 148 & 200 & 125 \\
\hline Desenvolvimento & 30 & 0 & 5 & 150 & 140 & 195 & 130 \\
\hline Protótipo & 15 & 5 & 0 & 150 & 130 & 170 & 110 \\
\hline Fotogravação & 180 & 150 & 150 & 0 & 15 & 35 & 642 \\
\hline Programação & 148 & 140 & 130 & 15 & 0 & 45 \\
\hline Colorimetria & 200 & 195 & 170 & 35 & 45 & 0 \\
\hline Produção & 125 & 130 & 110 & 642 & 90 & 685 & 0 \\
\hline
\end{tabular}

Tabela 5: Diagrama De-Para: Número de jornadas diárias

\begin{tabular}{l|c|c|c|c|c|c|c}
\hline \multicolumn{1}{c|}{ De / Para } & Alfândega & Desenvolvimento & Protótipo & Fotogravação & Programação & Colorimetria & Produção \\
\hline Alfândega & 0 & 0 & 0 & 2 & 4 & 0 \\
\hline Desenvolvimento & 0 & 0 & 30 & 16 & 8 & 44 \\
\hline Protótipo & 0 & 30 & 0 & 16 & 4 & 10 & 10 \\
\hline Fotogravação & 2 & 16 & 16 & 0 & 2 & 16 & 34 \\
\hline Programação & 4 & 8 & 4 & 2 & 0 & 2 \\
\hline Colorimetria & 0 & 10 & 10 & 16 & 2 & 0 & 26 \\
\hline Produção & 44 & 6 & 4 & 34 & 26 & 90 \\
\hline
\end{tabular}

Visando facilitar a observação das interligações, construiu-se a carta de interligação preferencial de todo o setor de customização (Figura 6).

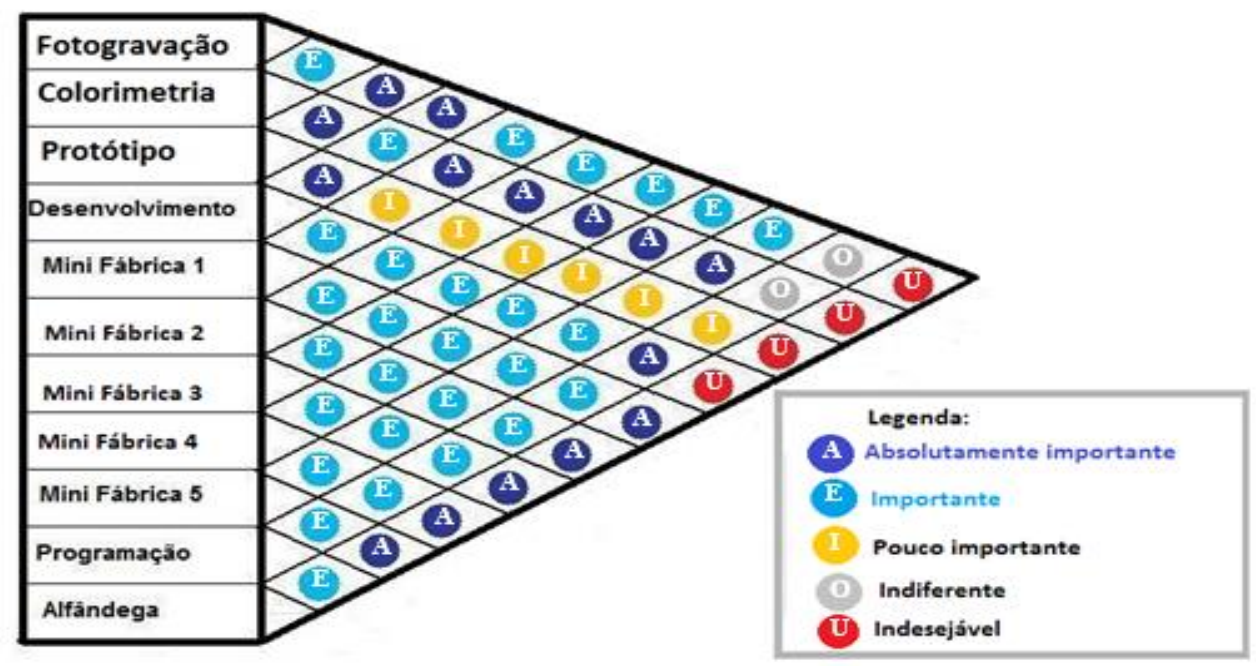

Figura 6: Carta de interligações preferenciais do chão de fábrica

Desmembrando-se a carta de interligações preferenciais, que mostra o grau de importância de proximidade entre cada setor a partir dos dados obtidos do fluxo entre cada um deles, tem-se o diagrama de interligação entre os setores, visualizado na Figura 7. 


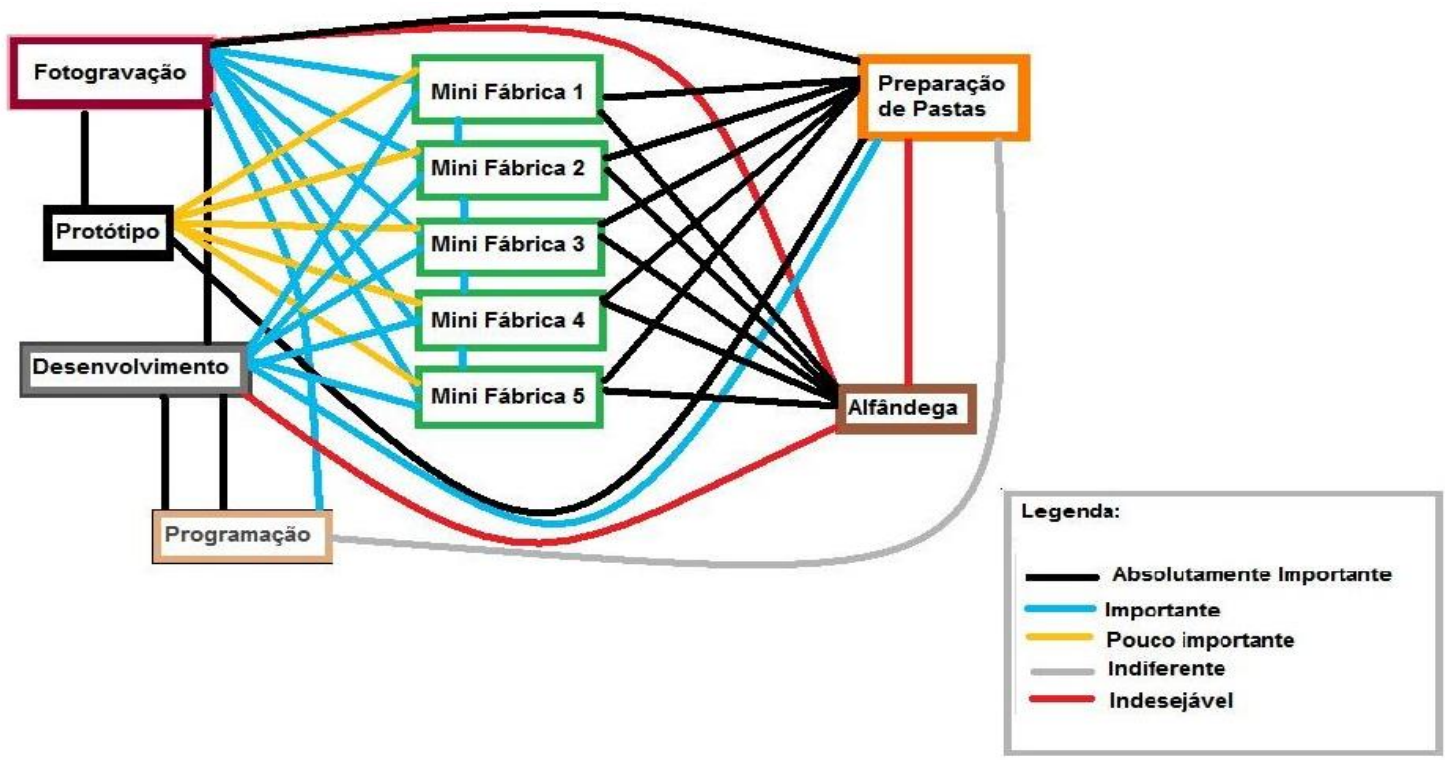

Figura 7: Diagrama de interligações estre os setores

\subsection{PROPOSTAS DE LAYOUT}

Buscando-se a otimização no fluxo de materiais no setor analisado, três propostas de layout com especificações diferentes foram desenvolvidas, cada uma com suas vantagens e desvantagens. Os setores responsáveis pelo desenvolvimento da arte, programação, fotogravação, protótipo e alfândega foram dispostos no projeto da maneira mais adequada, não mudando de local em nenhuma das propostas. Portanto, o que difere uma proposta da outra é a busca pela melhor organização do chão de fábrica.

\section{Proposta de Layout A}

A primeira proposta de layout tem como vantagem a localização dos carrosséis circulares nas pontas de cada esteira, com exceção apenas de um deles, que está na lateral. Ou seja, neste formato, os trabalhadores ficariam confortáveis em relação à operação e à temperatura próxima à área quente da polimerizadeira, evitando acidentes de trabalho por esses motivos.

Porém, algumas desvantagens estão presentes neste modelo. A primeira delas é a localização do setor da colorimetria próximo à passagem, exposto à visualização de visitantes. Este setor é um pouco desorganizado, pois lida-se com tintas, cores, pastas, colas, misturas e testes. Dessa 
forma, é indesejável que este setor se localize nessa área, mas neste modelo não há outra área suficiente disponível para esse fim.

Também foi analisado o deslocamento dos lugares iniciais das máquinas, pois as maiores máquinas teriam de ser desmontadas caso não ficassem próximas às suas localizações. Isso atrasaria o processo de mudança, que deveria ser feito nas férias coletivas, em um período de 20 dias. Outra desvantagem deste modelo é a proximidade entre algumas máquinas, o que resulta em desconforto para o trabalhador, podendo gerar acidentes de trabalho.

\section{Proposta de Layout B}

Nesta proposta, todos os carrosséis circulares, que apresentam seis metros de diâmetro, estão localizados nas laterais das esteiras. Isso significa que, se um carrossel desse formato ficar na lateral de uma esteira, deve haver uma distância de segurança para que os operadores atuem com conforto. Porém, neste caso, o carrossel circular ficaria distante e o operador que retira a peça da máquina teria de caminhar mais de três passos para depositar a peça na esteira, o que atrasaria a operação e, consequentemente, a produtividade do setor.

Outra desvantagem deste modelo é o tamanho do setor da colorimetria, que, por falta de espaço, teria de ser reduzido, o que poderia futuramente atrapalhar a realização das atividades.

\section{Proposta de Layout C}

Analisando os prós e os contras das duas primeiras propostas, foi projetado um terceiro modelo, que atenderia aos principais requisitos esperados:

- menor movimentação das máquinas durante a modificação do layout, fazendo com que o processo de modificação ocorra no tempo previsto de 20 dias, não sendo necessário o desmonte de nenhuma das máquinas. Caso isso ocorresse, poderia atrasar o andamento das atividades, perdendo-se dias de produção;

- colorimetria no tamanho ideal e localizada em um canto reservado, contribuindo para a perfeita realização das atividades e evitando a exposição deste setor; 
- colorimetria centralizada entre as máquinas, aumentando a integração e diminuindo o tempo de resposta, além de reduzir significativamente o fluxo de pessoas e materiais;

- melhor espaçamento entre as máquinas e maior espaço no setor;

- carrosséis circulares localizados nas pontas das esteiras, contribuindo para a saúde e o conforto do operador.
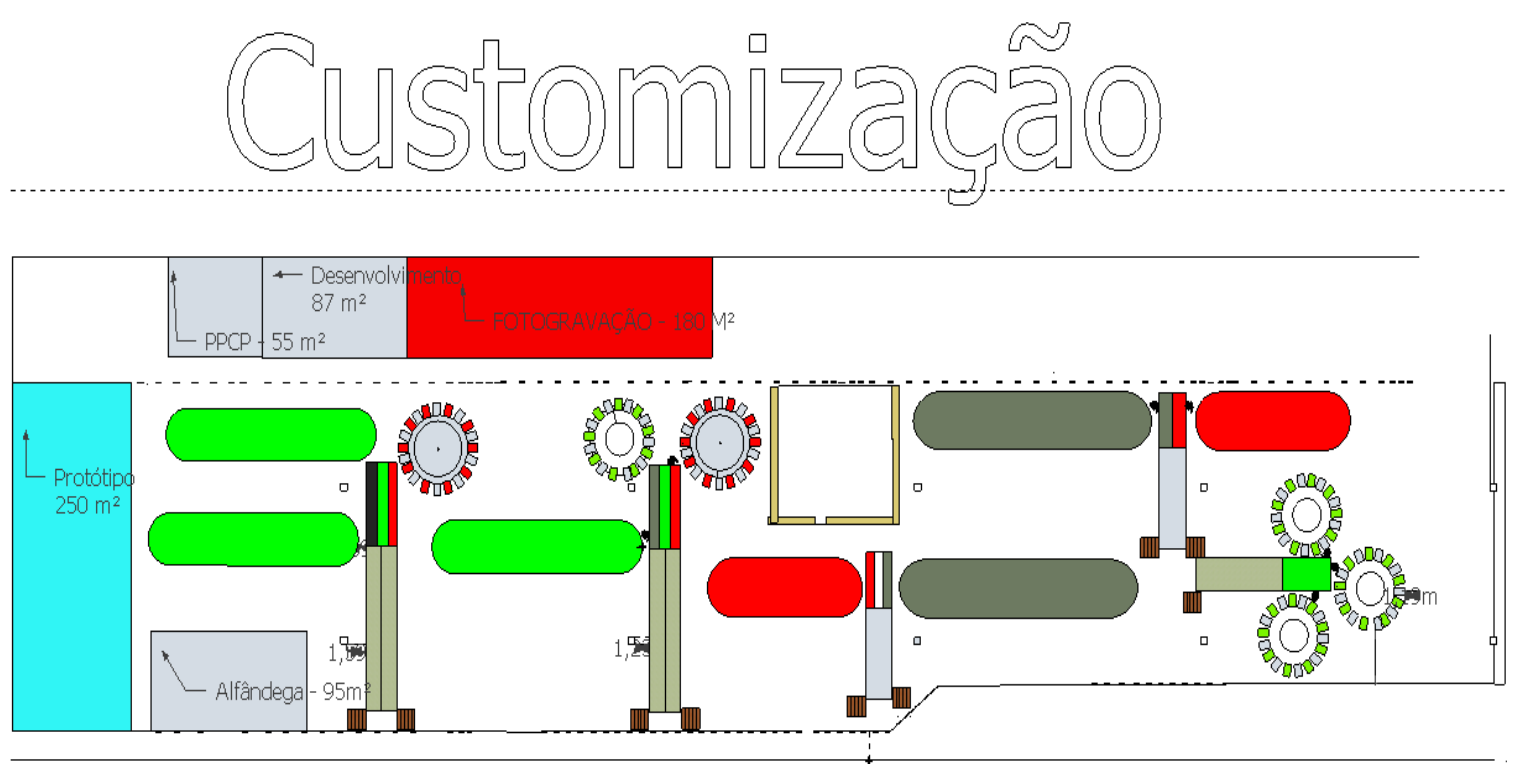

Figura 8: Proposta aprovada de novo layout

A diretoria da empresa aceitou a terceira proposta de Layout (Figura 8), e a modificação foi implementada no período de férias coletivas. Na Figura 9, expõe-se o mapeamento do processo após a implementação do novo layout.
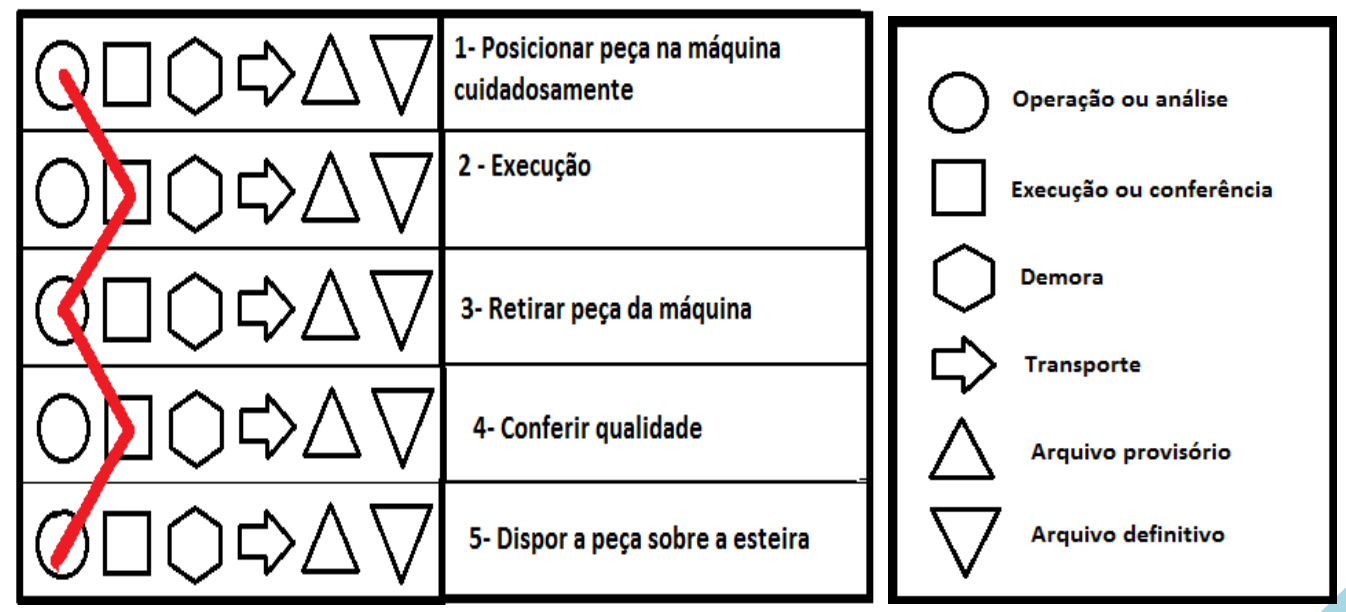


\section{Figura 9: Mapeamento do processo após implementação novo layout}

Depois da implementação da nova proposta de layout, verificou-se a eliminação completa das operações que não agregavam valor ao produto, conforme se mostra na Figura 9.

\section{CONCLUSÕES}

A otimização dos processos é uma das principais formas de manter a competitividade de empresas, assim o objetivo deste trabalho foi demonstrar melhorias auferidas com a modificação do layout do setor de customização da maior indústria de confecção de vestuário da América Latina. A implementação de um novo layout no setor de customização possibilitou a eliminação do maior fluxo de deslocamento que existia entre os carrosséis e as esteiras, que era de aproximadamente 16 quilômetros por dia. Essa mudança contribui significativamente para a eficiência e a eficácia do setor analisado.

O fluxo entre os carrosséis e a colorimetria, que no layout anterior era responsável por quase dez quilômetros de deslocamento diário, foi reduzido significativamente. Além da redução dos fluxos, outro benefício auferido com a implementação do novo layout foi a maior integração entre as máquinas. Essa integração possibilitou melhor comunicação entre os operadores, os quais agora têm ações rápidas na contenção de problemas de produção.

Analisando-se, ainda, o fluxo de materiais, pessoas e informações, pode-se enfatizar a ocorrência de maior proximidade e integração entre os demais setores dos quais a produção depende, o que gerou um aumento da eficiência, tanto de ordem física quanto de ordem cognitiva, contribuindo para maior percepção de todos os setores quanto aos problemas dos seus antecessores ou sucessores, seguindo a ordem do processo.

A produção, que antes era feita por remessas, agora é uma produção contínua. Ou seja, a produção pode ser liberada em partes para a costura, sem que seja necessária a conclusão da remessa para que isso ocorra. Todos esses fatores citados anteriormente contribuíram 
significativamente para a redução do lead time da peça no setor, atingindo um dos objetivos do trabalho.

Outros impactos positivos da modificação do layout foram a redução da quantidade de operadores no setor de customização, os quais foram remanejados para outros setores da indústria; aumento da qualidade final do produto, com redução de perdas e retrabalho; e melhoria das condições ergonômicas dos operadores.

\section{REFERÊNCIAS}

Associação Brasileira da Indústria Têxtil e de Confecções - ABIT. (2008). Recuperado em 12 de julho, 2012, de http://www.abit.org.br

Banco Nacional de Desenvolvimento Econômico e Social - BNDES. (2015). BNDES Setorial (42, 17-50). Rio de Janeiro: Banco Nacional de Desenvolvimento Econômico e Social.

Britto, G. L., Melo, I. G. G., Arcieri, A. M. A., \& Barreto, F. R. (2015). Aplicação da metodologia slp na melhoria do layout de uma linha de produção de chuveiros. Anais do Encontro Nacional de Engenharia de Produção - ENEGEP, 35, Fortaleza, CE, Brasil.

Corrêa, H. L., \& Corrêa, C. A. (2006). Administração de produção e operações (2a ed.). São Paulo: Atlas.

Emami, S, \& Nookabadi, A. S. (2013). Managing a new multi-objective model for the dynamic facility layout problem. International Journal of Advanced Manufacturing Technology, 68, 2215-2228.

Francischini, P. G., \& Fegyveres, A. (1997). Arranjo físico. In J. C. Contador (Coord.), Gestão e operações: a engenharia de produção a serviço da empresa (pp. 155-164). São Paulo: Edgard Blucher;Fundação Vanzolini.

Gaither, N., \& Frazier, G. (2001). Administração da produção e operações (8a ed.). São Paulo: Pioneira Thomson Learning.

Garcia-Diaz, A., \& Smith, J. M. (2008). Facilities planning and design. Upper Saddle River: Prentice Hall.

Gil, A. C. (2009). Como elaborar projetos de pesquisa. São Paulo: Atlas.

Lin, Q. L., Liu, H. C., Wang, D. J;, \& Liu, L. (2013). Integrating systematic layout planning with fuzzy constraint theory to design and optimize the facility layout for operating theatre in hospitals. Journal of Intelligent Manufacturing, 26(1), 87-95.

Muther, R. (1973). Systematic layout planning (2nd ed.). Boston: Cahners Books. 
Muther, R., \& Wheeler, J. D. (2000). Planejamento simplificado de layout: sistema SLP. São Paulo: IMAM.

Pelissari, A. S., Gonzalez, I. V. F. P., \& Vanalle, R. M. (2011). Gestores de pequenas empresas: estudo do papel e das funções gerenciais. Anais do Simpósio de Excelência em Gestão e Tecnologia - SEGeT, 4, Resende, RJ, Brasil.

Petry, C. (2015). Proposta de arranjo físico através do método SLP em um ambiente operacional de uma empresa de comunicação visual. Trabalho de Conclusão de Curso, Universidade Tecnológica Federal do Paraná: PR, Brasil.

Schmenner, R. W. (1995). Service operations management. Englewood Cliffs: Prentice Hall.

Silva, E. L., \& Menezes, E. M. (2005). Metodologia da pesquisa e elaboração de dissertação (4a ed.). Florianópolis: UFSC.

Slack, N., Chambers, S., \& Johnston, R. (2009). Administração da produção (3a ed.). São Paulo: Atlas.

Tompkins, J., \& White, J. (1984). Facilities planning. Wiley: New Jersey.

Tortorella, G. L., \& Fogliatto, F. S. (2008). Planejamento sistemático de layout com apoio de análise de decisão multicritério. Production, 18(3), 609-624.

Villar, A. M., \& Nóbrega Júnior, C. L. (2004). Planejamento das instalações industriais. João Pessoa: Manufatura. 